\title{
An Exploration of Registered Dietitian Accreditation System Development in China
}

\section{Xiaoli Wang}

Chinese Nutrition Society

Yajie Zhang

Chinese Nutrition Society

Ya Liu

Chinese Nutrition Society

Xiuhua Shen

Chinese Nutrition Society

\section{Rong Xiao}

Chinese Nutrition Society

Huilian Zhu

Chinese Nutrition Society

\section{Guo Zeng}

Chinese Nutrition Society

Yuexin Yang ( $\nabla$ yuexin_yang@sina.com )

Chinese Nutrition Society

\section{Wei Cai}

Chinese Nutrition Society

\section{Aiguo Ma}

Chinese Nutrition Society

\section{Research Article}

Keywords: dietetic education, dietetic professional, registered dietitian, dietetic accreditation

Posted Date: January 10th, 2022

DOI: https://doi.org/10.21203/rs.3.rs-1195013/v1

License: (a) (i) This work is licensed under a Creative Commons Attribution 4.0 International License. Read Full License 


\section{Abstract}

\section{Background:}

To review the highlights of the registered dietitian accreditation system in China, including history, organization, regulatory policies, certification requirements, development, and performance on the certification examination, registration, and continuing education, the process for the accreditation system development was focused. The data from the certification examinations and registrations were collected and analyzed. The eligibility requirements, as well as practice pathways, were discussed. Lessons learned from the development of the registered dietitian accreditation system, opportunities, challenges, and future directions for the field were discussed. There remain needs for well-established degree programs and a professional organization's maintenance with endeavouring in job opportunities, as well as legislative concerns.

\section{Background}

Nutrition plays an essential role in human health, recognized in China as early as 12th century BC (Zhou Dynasty) that "Physician Specialized in Diet" as a profession was recorded in Rites of Zhou. $(1,2)$ In the early 20 century, the modern registered dietitian accreditation system originated and shaped the education and practice of dietitians as a profession of medical team in western countries.(3) Meantime, there were several dietetic programs with a bachelor's degree in China, while Peking Union Hospital had a similar dietitian training system as it had in the United States. $(4,5)$ However, the programs had been suspended in 1952.(5) At later stage, although there were two majors in Medical Nutrition and Nutrition and Food Hygiene recovered,(6) dietitian was listed as "medical technicians" with limited payment and career development. $(4,5)$ As a result, most professionals who worked in hospitals' nutrition departments were physicians but not dietitians until the recent two decades.(5)

In 2004, the Ministry of Education of China established a four-year undergraduate major in Food Hygiene and Nutrition, while Shanghai Jiao Tong University was the first school to offer this major. $(4,7)$ To build a team of dietitians with guaranteed competencies, quantity, professionalism, and ethics, as the only nationwide nutritional science academic group in China, the Chinese Nutrition Society (CNS) began to design a registered dietitian accreditation system in 2014.(8) In 2016, the government started to promote de-regulation and improve service, thus the government-led vocational qualification certification was gradually transferred to professional level evaluation, with the participation of professional institutions and academic associations.(9) In this context, CNS assembled a particular committee to set sail of the dietetic certifications in accordance with international models.(8)

In 2015, CNS and Shanghai Jiao Tong University jointly initiated the training and certification of registered dietitians based on international standards. In May of 2016, the first registered dietitian examination (pilot) was successfully held in Shanghai. $(8,10)$ 
Now it has been six years since its inception. This article reviews the highlights of the registered dietitian accreditation system in China, including its history, organization, regulatory policies, certification requirements, development of and performance on the certification examination, registration, and continuing education. A brief analyses and prospect are discussed as well.

\section{The Rd/dtr Accreditation System In China Organization}

CNS is the organization responsible for the accreditation system of registered dietitians in China. Founded in 1945, CNS is a nationwide, non-profit academic organization dedicated to bringing nutrition scientists and professionals together to advance nutrition science and support the dissemination and application of nutrition to improve human well-being and prevent disease in China and the world. Currently, CNS has over 35,000 members in 31 provinces across China, including academic professionals, nutritionists, registered dietitians, health professionals, educators, and students interested in pursuing a nutrition career.(11)

In December 2016, the Registered Dietitian Committee (RDC) was formally established by CNS. The Committee recruited dietetics and nutrition experts from universities, hospitals, and centers of disease control in a total of 45 representatives. The Committee consists of two branches that one is responsible for education and examinations, while the other is responsible for registration, supervision, and regulation. The Education and Training Department of the Secretariat of CNS is responsible for daily management.(12)

The Committee is also responsible for didactic and internship program evaluation and accreditation. Institutions could apply to the Committee for program accreditation. The Committee then assesses and evaluates the applications. The accreditation and regulation aim to support the academic institutes in providing course setting plans and corresponding curricula to emphasize skill practice throughout the knowledge learning schoolwork, while the internship spots with competencies standards. At present, 45 degree programs are fulfilled the curriculum setting and faculty team requirement, including 12 "double first-class universities" in 27 provinces, autonomous regions, and municipalities across the country. Among the approved institutions, 41 can train both registered dietitians (RDs) and dietetic technicians, registered (DTRs), while 4 can train solely DTR (Appendix 1). By now, 115 accredited internship programs meet the criteria including hospitals, community and companies, etc. $(13,14)$

\section{Regulation}

The Committee draws on the advanced experience of the International Confederation of Dietetic Associations (ICDA), the United States, Japan, as well as other countries and regions. Considering local facts, it has established a series of provisions and regulations of the registered dietitian accreditation system,(15) including Interim Provisions on the Level Evaluation System of Registered Dietitians, 
(16) Implementation of the Level Evaluation Examination of Registered Dietitians,(17) Interim Measures for the Management of Continuing Education of Registered Dietitians,(18) Regulations of Didactic and Internship Programs Accreditation, and Professional Code of Ethics and Competency Standards.(15)

\section{Pathway to Be an RD/DTR}

According to the provisional and regulatory documents released, the credentialing process to be an RD or a DTR includes the corresponding curricula, internship, examination, registration and re-registration which were summarized in Table 1.(16)

Table 1. The Criteria for RD and DTR Registration

\begin{tabular}{|c|c|c|}
\hline & Registered Dietitian & Registered Dietetic Technicians \\
\hline \multirow[t]{2}{*}{$\begin{array}{l}\text { Academic } \\
\text { Coursework* }\end{array}$} & $\begin{array}{l}\text { 1) Complete a minimum of a bachelor } \\
\text { degree in dietetics and nutrition } \\
\text { majors }\end{array}$ & $\begin{array}{l}\text { 1) Complete a minimum of an associate's } \\
\text { degree in dietetics and nutrition majors or } \\
\text { a bachelor degree in any majors }\end{array}$ \\
\hline & $\begin{array}{l}\text { 2) Complete a series of required } \\
\text { courses for Registered Dietitians (see } \\
\text { Appendix } 1 \text { ) and acquire } \\
\text { corresponding credits }\end{array}$ & $\begin{array}{l}\text { 2) Complete a series of required courses } \\
\text { for Registered Dietetic Technicians (see } \\
\text { Appendix 1) and acquire corresponding } \\
\text { credits }\end{array}$ \\
\hline Internship* & $\begin{array}{l}\text { Work in nutrition and nutrition-related } \\
\text { fields or complete the dietetic } \\
\text { internship for at least one year }\end{array}$ & $\begin{array}{l}\text { Work in nutrition and nutrition-related } \\
\text { fields or complete the dietetic internship } \\
\text { for at least one year }\end{array}$ \\
\hline Examination $\star \star$ & Pass the exam & Pass the exam \\
\hline $\begin{array}{l}\text { Registration } \\
\text { (re- } \\
\text { registration*) }\end{array}$ & Apply to the Committee & Apply to the Committee \\
\hline $\begin{array}{l}\text { Continuing } \\
\text { Education }{ }^{\star \star \star}\end{array}$ & 50 credits in five years & 30 credits in five years \\
\hline
\end{tabular}

Abbreviations: RD, registered dietitian; DTR, dietetic technicians, registered.

Notes: * Interim Provisions on the Level Evaluation System of Registered Dietitians; ** Implementation of

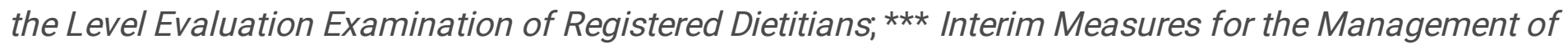
Continuing Education of Registered Dietitians.

\section{Academic Coursework}

The training of RD and DTR in China is based on degree education. At least a bachelor degree is required to obtain an RD credential, and an associate degree is required for DTR. The coursework modules required include general medicine, fundamental nutrition, food science and food safety, foodservice and 
management, community nutrition, human nutrition, clinical nutrition, nutrition education, and environment and health. The course requirements for RD and DTR differ in depth and credits that the detailed curricula are listed in Appendix 2.

\section{Internship}

For a competent RD/DTR, supervised practice is essential. The internship programs are divided into two categories. The first category consists of hospitals and clinics, centers of disease control, and companies. Those who want to become and RD or a DTR may choose to complete the internship in one or several different programs; the second category is based on the didactic programs that the universities and colleges organize and coordinate qualified resources to provide internship rotates, which is similar to the Coordinate Program in the United States. The full internship cumulative time of either type of the programs shall not be less than one year.

The practice could be in three professional fields: clinical, public, and food nutrition. Clinical nutrition is mainly aimed at hospitals and clinics, maternal and child health care centers, and other medical-related institutions; public nutrition is mainly aimed at centers for disease control and prevention, nursing homes, schools, community, and long-term care institutions; food nutrition is at food processing, catering management, foodservice management, and food safety-related enterprises.(13)

\section{Examination}

The ones who completed the didactic and internship programs would be eligible to sit for the registration exam.

The content of the RD examination is divided into four modules that 1) Individual and Group Nutrition Management accounts for $40 \%$ of the total, 2) Food and Nutrition, 3) Public Nutrition and Nutrition Education, and 4) Foodservice Management each accounts for $20 \%$; the content of the DTR examination has three modules that 1) Food Science and Foodservice Management accounts for $50 \%$ of the total, and 2) Individual and Group Nutrition Management and 3) Public Nutrition and Nutrition Education each accounts for $25 \%$. The grades would be announced three months after the exams.(17)

\section{Registration}

The candidates with a passing grade need to apply to the Committee for registration. Registration is valid for five years. One must apply to the Committee for re-registration three months before it expires. Candidates who are re-registered must meet the following criteria:(1) complete the minimum credit requirements for continuing education; (2) comply with the Code of Ethics; (3) the employers have no objection against the applicants in obtaining certificates of RD or DTR.(16) 


\section{Continuing Education}

To ensure the qualification's activeness, RD must obtain at least 50 credits, while DTR must obtain at least 30 credits in continuing education practices in 5 years after registered.(18)

The following educational activities account for claiming credits for the Continuing Education record: (1) participate in accredited Continuing Education courses for Registered Dietitian; (2) enroll in a full-time professional study for at least one month; (3) participate in academic conferences, professional workshops, and related training; (4) publish journal articles, presentations, or books; (5) accredited continuing education programs by either national, provincial or municipal government departments; conduct health promotion articles and books via newspaper, magazine, or selected platforms; attend academic conferences, and submit abstracts; others including participation in academic material compiling, teaching, and attaining a degree.(18)

\section{Review on the Examinations}

Since 2016, national registered dietitian examinations have been organized successfully for five consecutive years, including 4 RD exams and 2 DTR exams. Five examination sites are set up in Beijing, Shanghai, Guangzhou, Chengdu, and Changchun, relying on Capital Medical University, Shanghai Jiao Tong University, Sun Yat-Sen University, Sichuan University, and Jilin University. $(19,20)$ Since 2020, CNS has commissioned professional test agencies and the number of test sites has been increased to be in 15 cities.(21)

The pass rates were listed in Table 2. The first nationwide test was free of examination fees,(19) the Chinese Nutrition Society bears all costs, and the paper-based test RD 280 yuan/person/time,(22) DTR 200 yuan/person/time,(20) computer-based RD 380 yuan/person/time, DTR 300 yuan/person/time.(21)

Table 2. Statistics of RD and DTR Examinations

\begin{tabular}{|lllll|}
\hline Level & Year & Examinee & Pass & \% Pass \\
\hline RD & 2016 & 193 & 62 & $32.12 \%$ \\
\cline { 2 - 5 } & 2017 & 1414 & 509 & $36.00 \%$ \\
\cline { 2 - 5 } & 2018 & 2602 & 786 & $30.21 \%$ \\
\hline DTR & 2019 & 3443 & 1074 & $31.19 \%$ \\
& 2017 & 1053 & 697 & $66.68 \%$ \\
\hline & 2018 & 1562 & 856 & $54.80 \%$ \\
\hline
\end{tabular}

Abbreviations: RD, registered dietitian; DTR, dietetic technicians, registered. 
Table 3 listed the pass rate of test attendees with different degree levels from 2017 to 2019. In terms of $\mathrm{RD}$, the higher the degree of candidates, the higher the pass rate. The pass rate of doctoral students with a higher pass rate is more than $20 \%$, different from undergraduates with a lower pass rate. In terms of DTR, the pass rates for associates and bachelors are similar, and the pass rates for masters and doctors are similar, with a difference of about $20 \%$.

Table 3. Pass Rate of RD and DTR Examinations with Different Degree Levels

\begin{tabular}{|lllll|}
\hline Level & Degree Level & $\mathbf{2 0 1 7}$ & $\mathbf{2 0 1 8}$ & $\mathbf{2 0 1 9}$ \\
\hline RD & Bachelor's & $40 \%$ & $30 \%$ & $32.7 \%$ \\
\cline { 2 - 5 } & Master's & $51.9 \%$ & $41.9 \%$ & $42.4 \%$ \\
\cline { 2 - 5 } & Doctoral & $62.5 \%$ & $58.3 \%$ & $53.8 \%$ \\
\hline \multirow{2}{*}{ DTR } & Associate's & $64.16 \%$ & $50.69 \%$ & - \\
\cline { 2 - 5 } & Bachelor's & $62.39 \%$ & $54.64 \%$ & - \\
\hline & Master's & $82.25 \%$ & $70.71 \%$ & - \\
\hline & Doctoral & $83.33 \%$ & $57.14 \%$ & - \\
\hline
\end{tabular}

Abbreviations: RD, registered dietitian; DTR, dietetic technicians, registered.

Note: Absentees excluded.

\section{Analyses On Current Registered}

There are currently 5673 RDs (68.12\%) and 2655 DTRs (31.88\%), of which $80.58 \%$ are females, and $19.42 \%$ are males.

As 2017-2019 was the dietitian system's transition period, those who meet the academic requirements and have worked for more than 15 years in the field may apply for an exemption.(23) Also, an increasing number of overseas registered dietitians are returning to work in China. Chinese with foreign RD/DTR credentials from the United States, Canada, Australia, New Zealand, and Japan are also eligible to apply for an exemption.(24) The composition of credentials, including test passed, test waived and overseas exempted, and the geographical distribution are listed in Table 4. As shown, the geographical distribution of RD/DTR is extremely uneven, more than $63 \%$ of the total amount of RD/DTR are concentrated in 10 well-developed provinces and cities such as Guangdong, Beijing and Shanghai, etc.

Table 4. Selected Characteristics of Current Registered in China 


\begin{tabular}{|lc|}
\hline Variable & $\mathbf{n}=\mathbf{8 3 2 8}(\%)$ \\
\hline Level & $5673(68.12 \%)$ \\
\hline RD & $2655(31.88 \%)$ \\
\hline Gender & \\
\hline Female & $6711(80.58 \%)$ \\
\hline Male & $1617(19.42 \%)$ \\
\hline Composition of credentials & \\
\hline Test passed & $3897(46.79 \%)$ \\
\hline Test waived & $4375(52.53 \%)$ \\
\hline Overseas & $56(0.67 \%)$ \\
\hline Geographical distribution (top 10 and others) \\
\hline Guangdong Province (South) & $987(11.85 \%)$ \\
\hline Beijing (North) & $874(10.49 \%)$ \\
\hline Shanghai (East) & $727(8.73 \%)$ \\
\hline Zhejiang Province (East) & $554(6.65 \%)$ \\
\hline Jiangsu Province (East) & $533(6.40 \%)$ \\
\hline Sichuan Province (West) & $348(4.18 \%)$ \\
\hline Shandong Province (East) & $336(4.03 \%)$ \\
\hline Shanxi Province (Northwest) & $335(4.02 \%)$ \\
\hline Jilin Province (Northeast) & $313(3.76 \%)$ \\
\hline Liaoning Province (Northeast) & $289(3.47 \%)$ \\
\hline Others & $3032(36.41 \%)$ \\
\hline
\end{tabular}

Abbreviations: RD, registered dietitian; DTR, dietetic technicians, registered.

\section{Age}

The age ranges from 24-105 years old. As shown in Figure 1, RDs accounted for the highest proportion of 45-54 years old while the proportion of DTRs in 25-34 years old was the highest. The proportion of 
both RDs and DTRs aged less than 25 years old and over 65 years old is the smallest, accounting for less than $2 \%$ of the total.

\section{Educational Background}

According to Figure 2, the overall educational level of RDs is higher than that of DTRs. Bachelor's degree accounts for a large proportion of the qualifications of RDs and DTRs, reaching $53.39 \%$ and $54.95 \%$, respectively. In terms of master's degree and doctoral degree, the proportion of highly educated RDs was $45.27 \%$, which was significantly higher than $11.49 \%$ of DTRs. The gap between RDs and DTRs in master's degree is $20.61 \%$, while that in doctor's degree is $13.17 \%$. It is worth noting that even $0.79 \%$ of DTRs have a doctoral degree, while $1.34 \%$ of registered dietitians have an associate degree.

\section{Practice Areas}

As shown in Figure 3, both RDs and DTRs accounted for the highest proportion of working in hospitals and clinics, reaching $53.25 \%$ and $48.21 \%$, respectively. By comparing the occupational distribution of RDs and DTRs, it is not difficult to see that the proportion of RDs from enterprises, educational institutions, and Centers for Disease Control and Prevention is more than $10 \%$, while DTRs are mainly from business and community. Other practice areas such as research institutions, government departments, school nutrition, food service management, and long-term care are relatively low in proportions.

\section{Discussion And Conclusion}

China is the most populous country in the world. With economic development and improved awareness of nutrition, there have been enormous demands for competent dietitians. Qualified personnel are essential to provide nutrition care to the public were specified in the National Nutrition Plan 2017-2030 issued by the government in 2017. For example, it stipulates that "strengthen the establishment of clinical nutrition departments so that the ratio of dietitians to hospital beds shall reach 1:150." $(25,26)$ However, both the number and quality of dietitians in China are far from meeting the needs. Therefore, it is necessary and urgent to build a team of qualified and skilled dietitian with sufficient amount.

A six year review of the development of the registered dietitian accreditation system in China shows that great efforts have been made and significant progress have been achieved. The system has reached or approached the international standards in terms of certification standards, curriculum design, internship requirements, examination content, $(27,28)$ and pass rates. $(29,30)$ Given the system implementation is only in the primary stage, the amount of competent dietitians is still inadequate. There are currently only $0.67 \mathrm{RD} / \mathrm{DTR}$ per 100,000 people in China with uneven geographical distribution, which is much lower than around 194 in Japan(31) and 33 in the United States.(32) Hence, it would be a long way to keep the system effective. More data and research on competencies of RD/DTR would be needed so that the system could be improved continuously. 
Based on the consideration above, in the forthcoming years, the following aspects should be focused: 1) Promote academic education and supervised practice in dietetics, strengthen the discipline construction of dietetics majors, expand the number of qualified programs; 2) Conduct follow-up surveys of certified dietitians entering the workplace to understand the actual knowledge and skill needs for the profession to better meet market needs; 3 ) Create a favorable and supportive policy environment in the health industry, encourage more highly educated talents to engage in health and nutrition field to protect the health, safety, and welfare of the public.

\section{Declarations}

Ethics approval and consent to participate

The research has been approved by National Health Commission of the People's Republic of China.

Consent for publication

Not applicable

Availability of data and materials

The datasets used and/or analyzed during the current study are available from the corresponding author on reasonable request.

Competing interests

Authors declare that they have no competing interests.

Funding

This work was supported by Training and Evaluation Standards of Dietitian, National Health Commission of the People's Republic of China and China Association for Science and Technology [the grant is in contract form with no assigned number].

Authors' contributions

$Y Y, W C, A M, X W$ and $Y Z$ contributed to the conception of the study; $Y Z$ and $W X$ organized and executed the research; $X W$ and $Y Z$ contributed significantly to analysis and manuscript preparation; $Y Z$ performed the data analysis and wrote the manuscript; $Y L, X S, R X, L Z$, and $G Z$ helped organizing the research; WC, $X W$ and $X S$ reviewed the analysis with constructive discussions. All authors approved the final version of the manuscript.

Acknowledgements

This work was supported by every member in the Chinese Registered Dietitian Committee, as well as the academic and practical institutions who explore and develop the groundbreaking enterprise with us. We 
also would like to express our gratitude to the editor and reviewers for helping us improve our manuscript.

\section{Abbreviations}

CNS, Chinese Nutrition Society (CNS)

CDC, Centers for Disease Control and Prevention

$\mathrm{RD}$, registered dietitian

DTR, dietetic technicians, registered

\section{References}

1. Liu Y, Habberstad L. The life of a text: A brief history of the Liji (Rites Records) and its transmission. Journal of Chinese Literature and Culture. 2014;1(1-2):289-308.

2. Chen XD. Brief research on the theory of cold and heat of the foods in Zhou Li (The rites of Zhou) [in Chinese]. Chinese Journal of Medical History. 2007;37(4):248-50.

3. Stein K, Rops M. The commission on dietetic registration: Ahead of the trends for a competent $21 \mathrm{st}$ century workforce. J Acad Nutr Diet. 2017;117(10):S45-S61.e7.

4. Shen X, Tang W, Yu Z, Cai W. The history and development of registered dietitian accreditation systems in China and other comparable countries. Nutr Res. 2019;70:11-7.

5. Shen XH, Tang WJ, Cai W. An exploratory research on Chinese dietitian's education system [in Chinese]. Chinese Journal of Medical Education. 2012;32(6):848-9.

6. Shen XH, Mao XX, Cai W. Discussion on dietitian's education system [in Chinese]. Chinese Journal of Clinical Nutrition. 2013;21(1):47-8.

7. Department of Nutrition School of Medicine SJTU. Introduction of Department of Nutrition School of Medicine, Shanghai Jiaotong University [Available from:

https://www.shsmu.edu.cn/yyx/info/1053/1440.htm.

8. CNS Registered Dietitian Commission. The first annual meeting of the Registered Dietitian Committee of the Chinese Nutrition Society was held [in Chinese] 2016 [updated December 17, 2016. Available from: http://www.crdietitian.org/industry/431720202.html.

9. The State Council PRC. China eases qualification requirements 2016 [updated December 8, 2016. Available from:

http://english.www.gov.cn/policies/latest_releases/2016/12/08/content_281475510947723.htm. 
10. Shanghai Jiao Tong University Department of Nutrition of the School of Medicine. The Shanghai Jiao Tong University Department of Nutrition of the School of Medicine hosted the first certification ceremony for registered dietitians in China [in Chinese]. Shanghai Jiao Tong University Newspaper. 2017 Janurary 9, 2017;Sect. 03 (col. 03).

11. Chinese Nutrition Society. About CNS [Available from: http://en.cnsoc.org/aboutUs/.

12. CNS Registered Dietitian Commission. The Committee of Chinese Registered Dietitian [in Chinese] [Available from: http://www.crdietitian.org/function/.

13. CNS Registered Dietitian Commission. Notification of the result of evaluation and approval of the RD/DTR internship programs [in Chinese] 2019 [updated March 6, 2019. Available from: http://www.crdietitian.org/notice/631900200.html.

14. CNS Registered Dietitian Commission. List and contact information of RD/DTR didactic programs [in Chinese] 2019 [Available from: http://www.crdietitian.org/learning/231820201.html.

15. CNS Registered Dietitian Commission. Provisional and regulatory documents [in Chinese] 2016 [Available from: http://www.crdietitian.org/specification/.

16. CNS Registered Dietitian Commission. Interim provisions on the level evaluation system of registered dietitians [in Chinese] 2016 [updated April, 2018. Available from: http://www.crdietitian.org/specification/231700200.html.

17. CNS Registered Dietitian Commission. Implementation of the level evaluation examination of registered dietitians [in Chinese] 2017 [updated March 3, 2017. Available from:

http://www.crdietitian.org/specification/741710203.html.

18. CNS Registered Dietitian Commission. Interim measures for the management of continuing education of registered dietitians [in Chinese] 2018 [updated August 6, 2018. Available from: http://www.crdietitian.org/specification/681800200.html.

19. CNS Registered Dietitian Commission. Notice on 2017 RD level evaluation examination [in Chinese] 2017 [updated April 11, 2017. Available from: http://www.crdietitian.org/notice/441710200.html.

20. CNS Registered Dietitian Commission. Notice on 2018 DTR level evaluation examination [in Chinese] 2018 [updated September 28, 2018. Available from: http://www.crdietitian.org/notice/891820200.html.

21. CNS Registered Dietitian Commission. Notice on 2020 RD/DTR level evaluation examination [in Chinese] 2020 [updated October 19, 2020. Available from: http://www.crdietitian.org/notice/422001200.html.

22. CNS Registered Dietitian Commission. Notice on 2019 RD level evaluation examination [in Chinese] 2019 [updated April 18, 2019. Available from: http://www.crdietitian.org/notice/841910200.html. 
23. CNS Registered Dietitian Commission. Notice on application for exemption of RD/DTR [in Chinese] 2017 [updated March 7, 2017. Available from: http://www.crdietitian.org/notice/441710201.html.

24. CNS Registered Dietitian Commission. Notice on application for exemption of RD/DTR overseas [in Chinese] 2017 [updated December 7, 2017. Available from:

http://www.crdietitian.org/notice/421711200.html.

25. The State Council PRC. China issues national nutrition plan (2017-2030) [in Chinese] 2017 [updated July 13, 2017 Available from:

http://english.www.gov.cn/policies/latest_releases/2017/07/13/content_281475725038850.htm.

26. The State Council PRC. China issues national nutrition plan (2017-2030), full text [in Chinese] 2017 [updated June 30, 2017. Available from:

http://www.gov.cn/gongbao/content/2017/content_5213172.htm.

27. Japanese Ministry of Health Labor and Welfare. National Examination for Registered Dietitian [in Japanese] [Available from:

https://www.mhlw.go.jp/kouseiroudoushou/shikaku_shiken/kanrieiyoushi/about.html.

28. ICDA. International standards 2017 [Available from:

http://www.internationaldietetics.org/International-Standards.aspx.

29. CDR. Registration examination for dietitians group performance statistics October 1987 - June 2020 [Available from:

https://admin.cdrnet.org/vault/2459/web///RD\%20Group\%20Performance\%20Statistics\%20\%20June\%202020.pdf.

30. Japanese Ministry of Health Labor and Welfare. Results of the 34th National Examination for Registered Dietitian [in Japanese] [Available from: https://www.mhlw.go.jp/stf/newpage_10407.html.

31. Japanese Ministry of Health Labor and Welfare. Changes in the number of registered dietitians and dietitians [in Japanese] [Available from: https://www.mhlw.go.jp/content/000613303.pdf.

32. CDR. Registry statistics 2017 [updated Feburary 15, 2021. Available from: https://www.cdrnet.org/registry-statistics-new.

\section{Figures}




\section{Age}

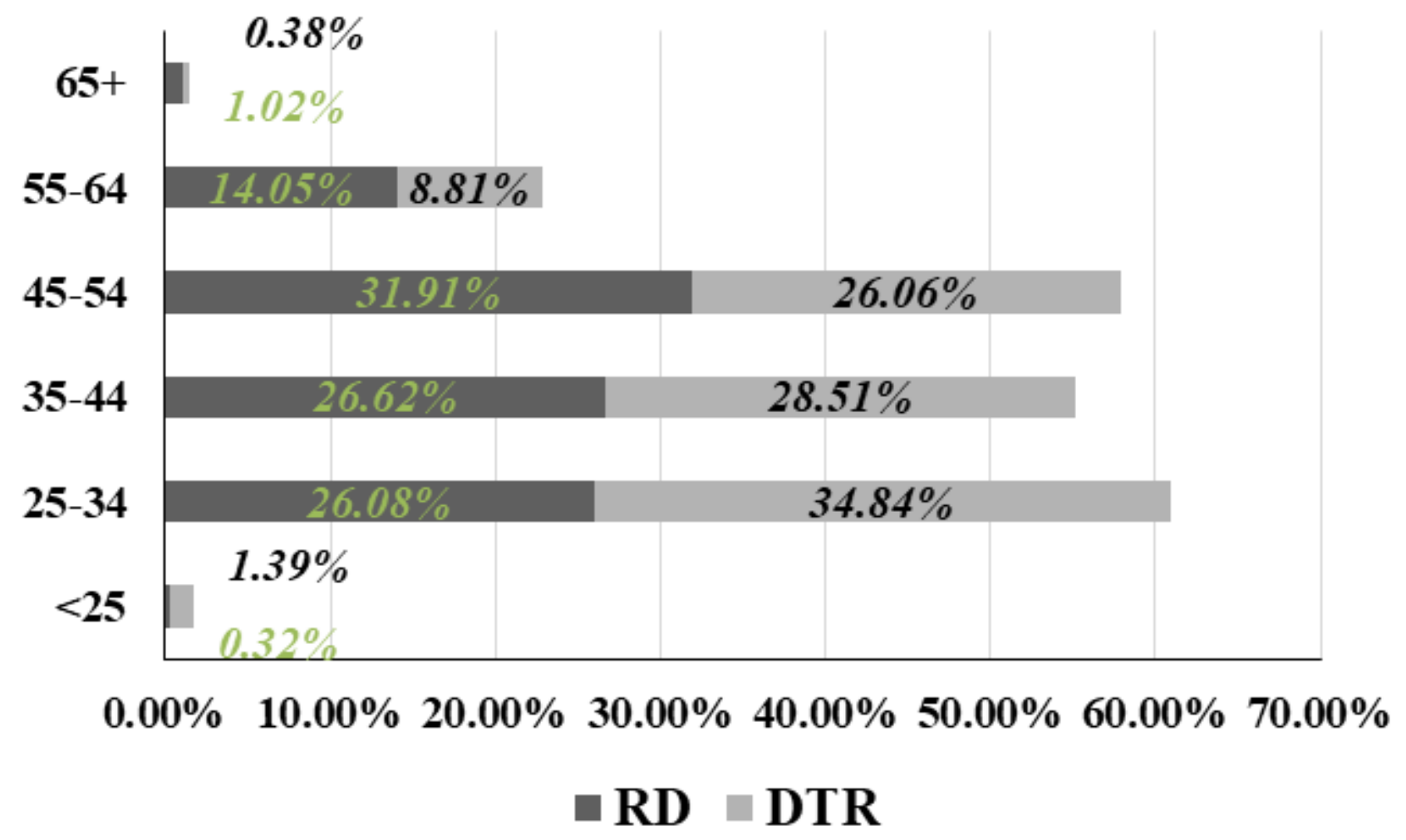

Figure 1

The age structure of RDs and DTRs. Abbreviations: RD, registered dietitian; DTR, dietetic technicians, registered. 


\section{Highest Degree Held}

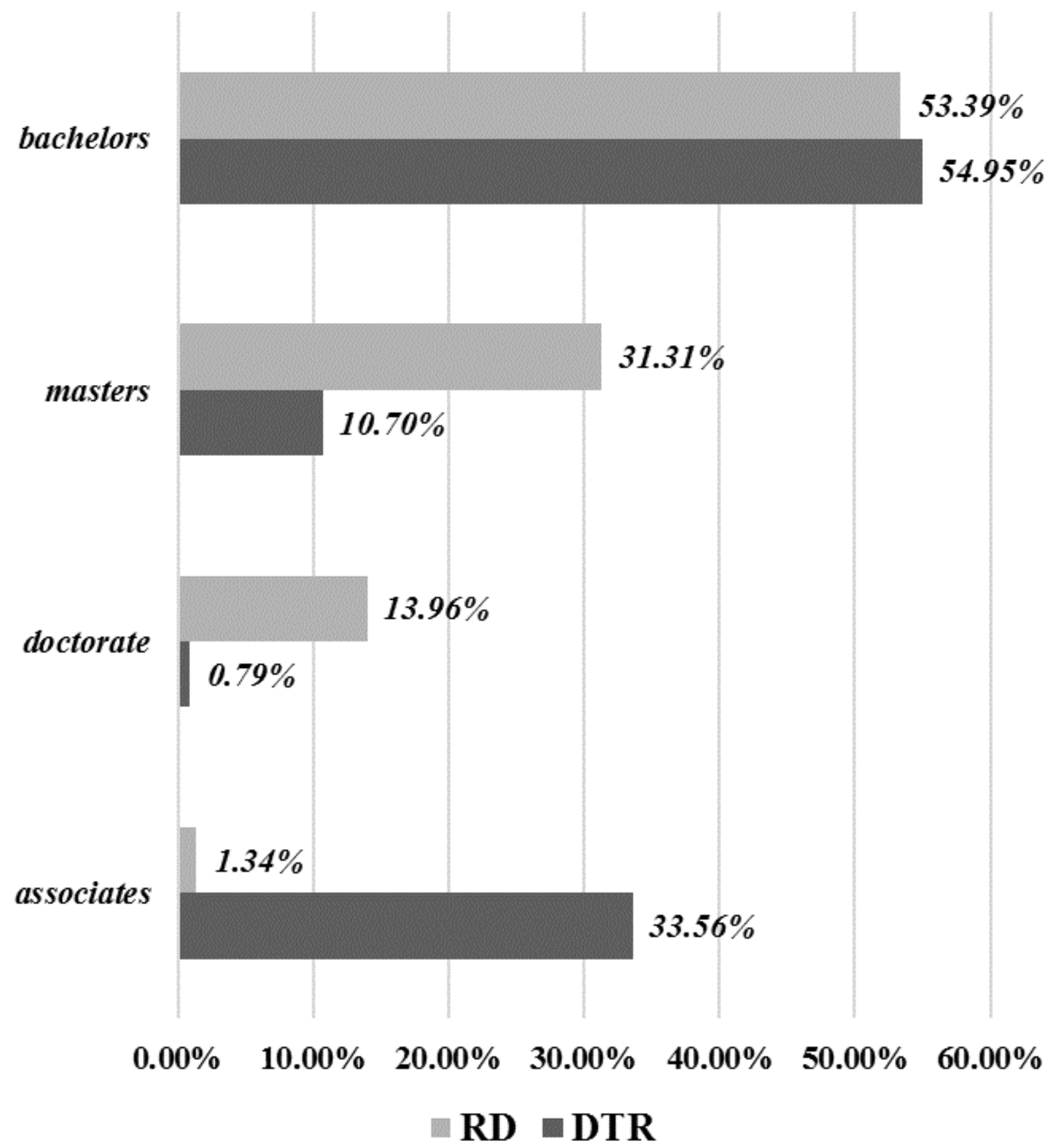

Figure 2

The education background of RDs and DTRs. Abbreviations: RD, registered dietitian; DTR, dietetic technicians, registered. 


\section{Practice Area}

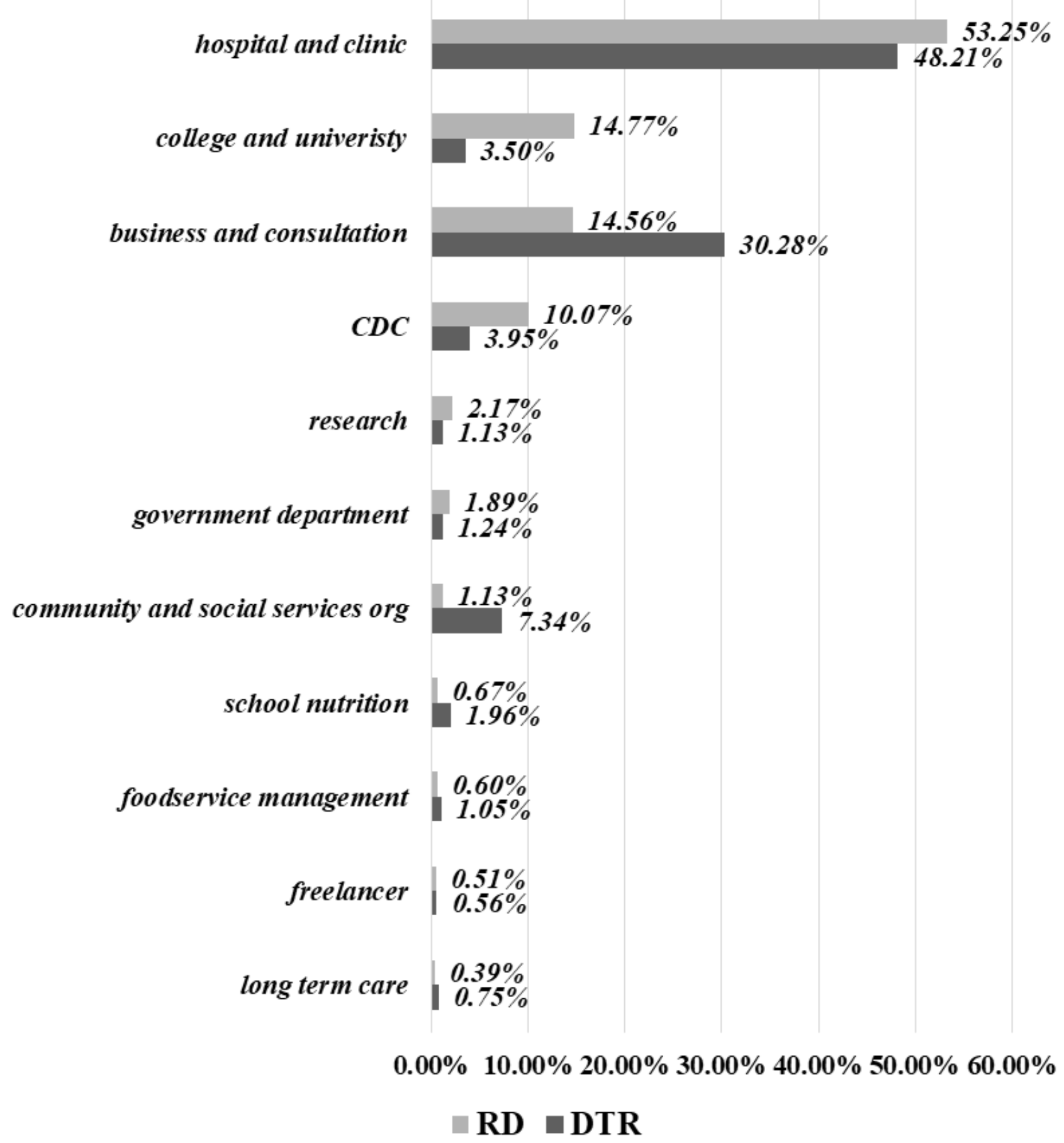

Figure 3

Practice Area of RDs and DTRs. Abbreviations: CDC, Centers for Disease Control and Prevention; RD, registered dietitian; DTR, dietetic technicians, registered.

\section{Supplementary Files}


This is a list of supplementary files associated with this preprint. Click to download.

- FM211116X706Appendixvfinal.docx 